\title{
Age of sexual maturation and adult spatial ability
}

\author{
DAVID C. GEARY \\ University of Missouri at Rolla, Rolla, Missouri \\ and \\ JEFFREY W. GILGER \\ University of Iowa, Iowa City, Iowa
}

(Ronald T. Kellogg, Sponsor)

\begin{abstract}
This paper describes a study designed to provide an extensive evaluation of the potential relationship between the age of sexual maturation and adult spatial ability. Data from two previous studies were combined to provide information on reasonably large samples of adult men $(n=133)$ and adult women $(n=116)$. Variables that represented the age of sexual maturation and scores on measures that span the Spatial Orientation ability factor were used in this reanalysis. The relationship between maturational timing and performance on the measures of spatial ability was examined from three perspectives: (1) correlations between indexes of maturational timing and the spatial measures, (2) correlations between variables derived from a signal-detection analysis of performance on the spatial measures and indexes of pubertal timing, and (3) a comparison of spatial ability for groups extreme in pubertal timing. In all, no consistent relationship between the age of sexual maturation and performance on the spatial orientation measures was found. Implications for the long-term relationship between maturational timing and individual differences in spatial ability are discussed.
\end{abstract}

It has been proposed that age of sexual maturation contributes to individual differences in the pattern of human cognitive abilities (Broverman, Broverman, Vogel, Palmer, \& Klaiber, 1964; Newcombe \& Dubas, 1987). Waber (1977) argued that gender differences in the age of pubertal onset might underlie the male performance advantage on measures of spatial-related ability and the female performance advantage on measures of language-related ability. Later maturation, independent of gender, was found to be associated with better performance on spatial ability measures; however, age of sexual maturation was not related to performance on measures of language-related ability. Several subsequent studies have replicated, or partially replicated, this relationship between age of pubertal onset and spatial ability in samples of adolescents (Diamond, Carey, \& Back, 1983; Newcombe \& Bandura, 1983; Waber, Bauermeister, Cohen, Ferber, \& Wolff, 1981), while other studies have failed to find such a relationship (Petersen, 1976; Waber, Mann, Merola, \& Moylan, 1985).

This research was partially supported by grants from the Graduate Division of the University of Missouri at Rolla, the UMR-Alumni Association, and AFOSR-88-0239 to the first author. The second author was supported by a postdoctoral fellowship in psychiatric genetics, NIMH-MH146201-12. We would like to thank Barbara Elliott-Miller, Dawn Elmore, Mona I. Brown, and Lynn Eisele for their assistance with data collection and collation. Correspondence and requests for reprints may be sent to David C. Geary, Department of Psychology, University of Missouri at Rolla, Rolla, MO 65401-0249.
Furthermore, several experiments have examined the relationship between the reported age of sexual maturation and performance on spatial ability measures for samples of adult subjects (Gilger \& Ho, 1989; Rierdan \& Koff, 1984; Sanders \& Soares, 1986; Strauss \& Kinsbourne, 1981). Neither Rierdan and Koff nor Strauss and Kinsbourne found any correlation between the reported age of menarche and performance on various spatial tests. Sanders and Soares, however, reported that an indicator of earlier-than-average, average, or later-than-average sexual development was significantly related to performance on the Mental Rotation Test (Vandenberg \& Kuse, 1978) for both samples of adult men and adult women. Here, later maturation was associated with higher scores on this spatial measure. These contradictory sets of findings indicate that the question of whether the age of sexual maturation contributes to individual differences in adult spatial ability is unresolved.

The present study was designed to clarify this issue by providing a rather extensive analysis of the potential relationship between the age of pubertal onset and adult spatial ability. To achieve this end, data from two recent studies (Geary, 1988; Geary, Gilger, \& Elliott-Miller, 1988) ${ }^{1}$ were combined to provide information on spatial ability and the age of sexual maturation for reasonably large samples of both adult men and adult women. In fact, the combined data provided a larger sample of adult males than was assessed in any of the above-noted studies (cf. Sanders \& Soares, 1986). Finally, portions of these data 
Table 1

Descriptive Statistics for the Spatial Ability Measures

\begin{tabular}{|c|c|c|c|c|c|c|}
\hline \multirow[b]{2}{*}{ Test } & \multicolumn{2}{|c|}{$M$} & \multicolumn{2}{|c|}{$S D$} & \multirow[b]{2}{*}{$t$ test } & \multirow{2}{*}{$\begin{array}{c}\text { Spearman-Brown } \\
\text { Reliability } \\
\text { Estimates } \\
\end{array}$} \\
\hline & Male & Female & Male & Female & & \\
\hline Mental Rotation & 18.6 & 9.4 & 10.0 & 8.4 & $7.76^{*}$ & .756 \\
\hline Card Rotations & 112.4 & 94.5 & 34.6 & 36.3 & $4.50 *$ & .923 \\
\hline Cube Comparisons & 21.9 & 15.8 & 10.1 & 11.5 & $3.97 *$ & .768 \\
\hline
\end{tabular}

were rescored for a signal-detection analysis of performance on measures that span the Spatial Orientation ability factor. This signal-detection analysis enabled a more sensitive test of the potential relationship between the age of sexual maturation and components of spatial ability than did previous studies (cf. Ho, Gilger, \& Brink, 1986).

\section{METHOD}

\section{Subjects}

The combined studies (Geary, 1988; Geary et al., 1988) provided information on 133 male and 116 female undergraduate students. The mean age of 20.4 years $(S D=3.4)$ and 19.9 years $(S D=3.6)$ for the males and females, respectively, did not differ significantly $(p>.10)$.

\section{Spatial Ability Measures}

Scores for both forms of the Mental Rotation Test (Vandenberg \& Kuse, 1978), the Card Rotations Test, and the Cube Comparisons Test (Ekstrom, French, \& Harman, 1976) were obtained for each of the 249 subjects. The score for each of these ability measures was the sum of scores on the two forms. Table 1 presents descriptive statistics and reliability estimates for the three spatial tests.

Protocols for 100 subjects (69 males, 31 females; Geary, 1988) were rescored in accordance with signal-detection analysis (Ho et al., 1986). Here, $d^{\prime}$ and beta $(\beta)$ scores were calculated for each of the three spatial measures. The $d^{\prime}$ score theoretically provides an indicator of the subject's ability to detect differences between standard and comparison stimuli, and $\beta$ provides an indicator of the rigor of the subject's criterion in accepting two stimuli as the same (Swets, 1964).

\section{Maturational Timing Indexes}

Menarcheal age was used as the indicator of pubertal timing for females. This single variable was chosen because retrospective reports of menarcheal age appear to be reliable (Geary, 1988) and valid (Bean, Leeper, Wallace, Sherman, \& Jagger, 1979). Two variables were chosen as indicators of maturational timing for males: (1) age of first ejaculation and (2) age at which hair growth was first noticed around the armpit area. The first variable, age of ejaculation, was employed because it provided an index of primary sexual development comparable to the age of menarche. The second variable was chosen on the basis of its relatively high level of test-retest reliability (Geary, 1988). Descriptive information for these maturational timing indexes are presented in Table 2.

\section{RESULTS}

\section{Correlations Between Maturational Timing Indexes and Spatial Ability Measures}

The top portion of Table 3 presents zero-order correlations between the three indexes of pubertal timing and scores on the tests of spatial ability. The composite score, which comprised the sum of $z$ scores for each of the three spatial measures, was included in the analyses because this score would likely provide a more sensitive index of spatial ability than would any of the single measures.
Regardless, inspection of Table 3 reveals that none of the 12 zero-order correlations between the pubertal indexes and the ability measures differed significantly from zero ( $p s>.10)$.

\section{Signal-Detection Analysis}

The bottom portion of Table 3 presents zero-order correlations between the variables, $d^{\prime}$ and $\beta$, derived from the signal-detection analysis and indexes of pubertal timing. Inspection of Table 3 reveals that only 1 of the 18 correlations differed significantly from zero $(p s>.05)$. Given no consistent pattern of correlations between the

Table 2

Descriptive Information for the Maturational Timing Indexes

\begin{tabular}{lcccc}
\hline \multicolumn{1}{c}{ Variable } & $M$ & $S D$ & $n$ & $\begin{array}{c}\text { Retest Reliability } \\
\text { Coefficient }\end{array}$ \\
Menarche & 12.70 & $\begin{array}{c}\text { Female } \\
\end{array}$ & \multicolumn{5}{c}{ Male } & 112 & .966 \\
Ejaculation & 14.01 & 2.16 & 111 & .730 \\
Armpit & 13.42 & 1.51 & 122 & .833 \\
\hline
\end{tabular}

Note-All ages are in years. Menarche $=$ age at which menstruation started; Ejaculation = age at which first ejaculation was noticed; Armpit $=$ age at which growth of hair in the armpit area was first noticed.

Table 3

Correlations Between Maturational Timing Indexes and Spatial Ability Measures

\begin{tabular}{lccr}
\hline & \multicolumn{3}{c}{ Maturational Timing Index } \\
\cline { 2 - 4 } Test & Menarche & Ejaculation & Armpit \\
\hline & Spatial Measures & & \\
Mental Rotation & .02 & .06 & -.04 \\
Card Rotations & -.08 & -.13 & .01 \\
Cube Comparisons & .03 & .01 & -.04 \\
Composite Score & -.01 & -.02 & -.03
\end{tabular}

Signal-Detection Measures

\begin{tabular}{llll}
$\begin{array}{l}\text { Mental Rotation } \\
\beta\end{array}$ & .26 & .01 & .01 \\
$\quad d^{\prime}$ & .10 & .13 & .08 \\
Card Rotations & & & \\
$\beta$ & .00 & -.04 & .04 \\
$\quad d^{\prime}$ & .25 & -.08 & .03 \\
Cube Comparisons & & & \\
$\beta$ & .01 & .11 & $.26 *$ \\
$d^{\prime}$ & .17 & .02 & -.04 \\
\hline
\end{tabular}

Note-Composite score $=$ summation of $z$ scores for the Mental Rotation, Card Rotations, and Cube Comparisons tests. Analyses for the signal-detection measures were based on $n=69$ for males and $n=$ 31 for females. ${ }^{*} p<.05$. 
signal-detection variables and the indexes of maturational timing, this single statistically significant correlation probably does not represent a replicable result. Finally, $d^{\prime}$ and $\beta$ scores were recalculated to control for the number of items attempted on each of the three spatial tests. The number of items attempted may index individual differences in the speed at which subjects approached test items. This additional analysis was conducted on the basis of Gilger and Ho's (1989) finding of a potential relationship between pubertal timing and the rate of adult twodimensional mental rotation. Zero-order correlations between the recalculated $d^{\prime}$ and $\beta$ variables and the indexes of maturational timing indicated no consistent relationship (there was one significant correlation) between these signal-detection variables and the reported age of sexual maturation. In fact, this pattern of correlations mirrored the original signal-detection analysis (described above).

\section{Extreme-Group Analysis}

The final set of analyses tested the hypothesis that the relationship between maturational timing and spatial ability is only detectable with the comparison of groups extreme in pubertal timing. The samples of males and females were trisected into groups that were earlier than average, average, or later than average in pubertal timing (Sanders \& Soares, 1986). The female sample was trisected on the basis of whether the reported menarcheal age was within $\pm 1 S D$ from the overall mean age of menarche for the average group $(n=88)$, less than 1 $S D$ from this mean for the earlier-than-average group $(n=15)$, and greater than $1 S D$ from this mean for the later-than-average group $(n=9)$. The means for these newly created groups (presented in Figure 1) differed significantly in value $(p<.0001)$.

The male sample was trisected on the basis of whether the reported age of first ejaculation was within $\pm 1 S D$ from the overall mean age of first ejaculation for the average group $(n=67)$, less than $1 S D$ from this mean for the earlier-than-average group $(n=19)$, and greater than 1 $S D$ from this mean for the later-than-average group $(n=25)$. The means for these three groups (also presented in Figure 1) differed significantly in value $(p<.0001)$. A similar variable was created for both the reported age of growth of hair around the armpit area and for a combi-

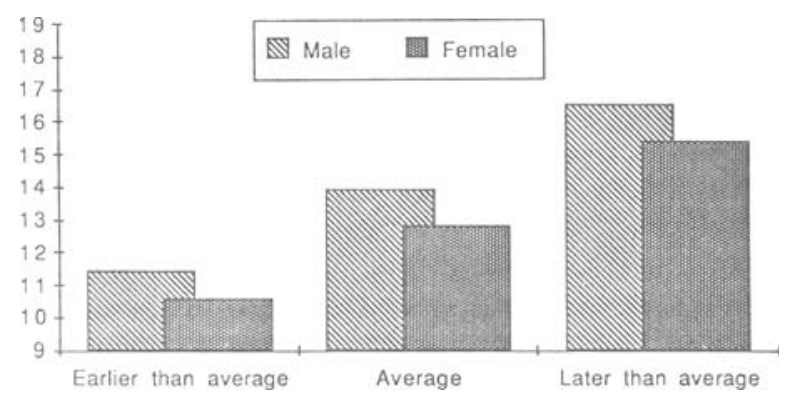

Figure 1. Mean age of primary sexual maturation for the earlierthan-average, average, and later-than-average groups. nation of the two maturational timing indexes. For the composite variable, the subjects again were classified as earlier than average, average, or later than average, but only the subjects who had received an identical classification (e.g., average) for the reported age of first ejaculation and for the age at which hair was first noticed around the armpit area were retained $(n=52)$. This final variable was used because it provided a more reliable and more valid indicator of the relative timing of puberty for males than did the two single variables.

Univariate ANOVAs were employed to determine if mean performance on the Mental Rotation Test, Card Rotations Test, Cube Comparisons Test, and the spatial composite variable differed significantly across the earlierthan-average, average, and later-than-average groups. None of the resulting $16 F$ ratios differed significantly from zero $(p s>.20)$. Post hoc comparisons of group means also indicated no significant relationship between the relative timing of sexual maturation and performance on any of the spatial measures.

\section{DISCUSSION}

The study examined the relationship between the reported age of sexual maturation and adult spatial ability from three perspectives: (1) zeroorder correlations between indexes of maturational timing and scores on spatial orientation ability measures, (2) correlations between indicators of pubertal timing and variables derived from a signal-detection analysis of performance on the spatial measures, and (3) a comparison of spatial ability across groups extreme in pubertal timing. The results associated with the first set of analyses were consistent with previous findings (Rierdan \& Koff, 1984; Sanders \& Soares, 1986; Strauss \& Kinsbourne, 1981). The reported age of occurrence of physical changes associated with primary and secondary sexual maturation showed no relationship to measured spatial ability.

The signal-detection analysis was unique to this study, and enabled us to, theoretically, disentangle an individual's ability to distinguish similar and dissimilar stimuli from his/her decision criterion, or strategy approach to the task (Swets, 1964). Both a subject's ability $\left(d^{\prime}\right)$ and a subject's decision criterion $(\beta)$ can influence the actual score on each of the spatial measures used in this study. Thus, the signal-detection analysis allowed for a potentially more sensitive test of the proposed relationship between the age of pubertal onset and components of spatial ability than did previous studies. Regardless, the variables derived from this analysis showed no consistent relationship to the reported age of sexual maturation.

The final group analysis, which classified the subjects as earlier-thanaverage, average, or later-than-average in the age of sexual maturation, also indicated no relationships between the relative timing of pubertal onset and adult spatial ability. This final set of results stands in contrast to the results presented in the Sanders and Soares (1986) study. The key to resolving these contradictory sets of findings might be found in the overall ability level of the subjects assessed in these two experiments. In all, the subjects assessed in the Sanders and Soares study appeared to be rather high in spatial ability (cf. Geary \& Widaman, 1987; Shute, Pellegrino, Hubert, \& Reynolds, 1983).

In fact, a comparison of mean performance on the Mental Rotation Test for our earlier-than-average $(M=10.5)$, average $(M=9.2)$, and later-than-average $(M=9.2)$ groups of females and the mean performance of identical groups presented in Sanders and Soares (1986, Figure 4) indicates that the mean for each of the three groups in this study was lower than was the mean for the lowest ability group of females $(M=15.2)$ assessed by Sanders and Soares. Moreover, the mean performance on the Mental Rotation Test (means ranged from 17.7 to 19.3) for each of the three groups of males (on the basis of the relative timing of first ejaculation) in this study was comparable to the mean 
performance of the earlier-than-average (i.e., the lowest mean performance, $M=20.0$ ) group of males presented in Sanders and Soares.

Thus, it might be that the age of sexual maturation has a long-term influence on spatial ability but that this effect is only detectable with the comparison of groups extreme in pubertal timing and groups that are also skewed toward the high end of the distribution of spatial ability. However, our consistent findings of no relationship between the age of sexual maturation and performance on the measures of spatial ability leads us to conclude that the age of pubertal onset is not a primary influence on individual differences in adult spatial ability.

\section{REFERENCES}

Bean, J. A., Leeper, J. D., Wallace, R. B., Sherman, B. M., \& JAGGER, H. (1979). Variations in the reporting of menstrual histories. American Journal of Epidemiology, 109, 181-185.

Broverman, D. M., Broverman, I. K., Vogel, W., Palmer, R. D., \& KLAIBER, E. L. (1964). The automatization cognitive style and physical development. Child Development, 35, 1343-1359.

Diamond, R., CareY, S., \& BACK, K. (1983). Genetic influences on the development of spatial skills during early adolescence. Cognition, 13, 167-185.

Ekstrom, R. B., French, J. W., \& Harman, H. H. (1976). Manual for kit of factor-referenced cognitive tests. Princeton, NJ: Educational Testing Service.

GEARY, D. C. (1988). Sex-dimorphic behavior patterns, maturational timing, and gender differences in spatial ability. Manuscript submitted for publication.

Geary, D. C., Gilger, J. W., \& Elliott-Miller, B. (1988). Gender differences in spatial ability: $A$ test of alternative mechanisms. Manuscript submitted for publication.

GEARY, D. C., \& Widaman, K. F. (1987). Individual differences in cognitive arithmetic. Journal of Experimental Psychology: General, 116, 154-171.

GILGER, J. W., \& Ho, H. (1989). Gender differences in adult spatial ability: Their relationship to pubertal timing, adolescent activities and sex-typing of personality. Cognitive Development, 4, 197-214.

Ho, H., Gilger, J. W., \& BrinK, T. M. (1986). Effects of menstrual cycle on spatial information-processes. Perceptual \& Motor Skills, 63, 743-751.

NewCombe, N., \& Bandura, M. M. (1983). Effect of age at puberty on spatial ability in girls: A question of mechanism. Developmental Psychology, 19, 215-224.
Newcombe, N., \& DUBAS, J. S. (1987). Individual differences in cognitive ability: Are they related to timing of puberty? In R. M. Lerner \& T. T. Foch (Eds.), Biological-psychosocial interactions in early adolescence (pp. 249-302). Hillsdale, NJ: Erlbaum.

Petersen, A. C. (1976). Physical androgyny and cognitive functioning in adolescence. Developmental Psychology, 12, 524-533.

Rierdan, J., \& KoFF, E. (1984). Age at menarche and cognitive functioning. Bulletin of the Psychonomic Society, 22, 174-176.

SANDERS, B., \& SoARES, M. P. (1986). Sexual maturation and spatial ability in college students. Developmental Psychology, 22, 199-203.

Shute, V. J., Pellegrino, J. W., Hubert, L., \& Reynolds, R. W. (1983). The relationship between androgen levels and human spatial abilities. Bulletin of the Psychonomic Society, 21, 465-468.

Strauss, E., \& Kinsbourne, M. (1981). Does age of menarche affect the ultimate level of verbal and spatial skills? Cortex, 17, 323-326.

Swets, J. A. (1964). Signal detection and recognition by human observers. New York: Wiley.

VANDENBERG, S. G., \& KUSE, A. R. (1978). Mental rotation, a group test of three-dimensional spatial visualization. Perceptual \& Motor Skills, 47, 599-604.

WABER, D. P. (1977). Sex differences in mental abilities, hemispheric lateralization, and rate of physical growth at adolescence. Developmental Psychology, 13, 29-38.

Waber, D. P., Bauermeister, M., Cohen, C., Ferber, R., \& WolfF, P. H. (1981). Behavioral correlates of physical and neuromotor maturity in adolescents from different environments. Developmental Psychobiology, 14, 513-522.

Waber, D. P., Mann, M. B., Merola, J., \& Moylan, P. M. (1985) Physical maturation rate and cognitive performance in early adolescence: A longitudinal examination. Developmental Psychology, 21, 666-681.

\section{NOTE}

1. The relationship between the age of sexual maturation and adult spatial ability was not the major focus of either of these two studies. Moreover, the form of the analyses described within this manuscript differed substantially from those analyses conducted by Geary (1988) and Geary et al. (1988).

(Manuscript received October 26, 1988.) 